\title{
El deporte y la educación física escolar en Medellín
}

\section{Sport and school physical education in Medellín}

\author{
González Palacio, E.V. ${ }^{*}$, Padierna Cardona, J.C. ${ }^{2}$, Córdoba Arboleda, M. ${ }^{3}$, Escobar Barrera, J.M. ${ }^{4}$ y Gaviria García, N.A. ${ }^{5}$ \\ 1 Universidad de Antioquia y Universidad de San Buenaventura Medellin (Colombia). \\ 2 Universidad de Antioquia (Colombia). \\ 3 Universidad de San Buenaventura Medellin (Colombia). \\ 4 Universidad de Antioquia (Colombia). \\ 5 Universidad de Antioquia (Colombia).
}

\begin{abstract}
Resumen: El presente escrito es producto de investigación ${ }^{1}$. Pretendió identificar y describir la situación actual del deporte y la educación física escolar en el municipio de Medellín a partir de las apreciaciones de los docentes que atienden la educación básica primaria en el municipio de Medellín, para lo cual empleó el enfoque cuantitativo desde un estudio no experimental descriptivo, donde participaron 140 docentes de instituciones educativas públicas y privadas del Municipio de Medellín. Los principales aportes están en el contexto de las instituciones educativas y el deporte formativo, definiendo rutas de mejora para ambos escenarios desde dimensiones complementarias en políticas, infraestructura, formación pedagógica y disciplinar permanente para los profesionales que atiendan el área y sus acciones extraescolares. Llama la atención, que solo un 26,4 \% de los docentes que atienden el área en Primaria tienen formación específica en Educación Física, Recreación y Deporte, ninguno de los docentes participantes tiene título de doctor, solo un 26,4 \% de los docentes de Básica Primaria tienen dedicación exclusiva a Educación Física, recreación y deporte, entre otras conclusiones. Se genera así una ruta para el desarrollo pedagógico y disciplinar de los profesores de Educación Física, Recreación y Deporte de Básica Primaria que debe ser atendida desde el diseño de políticas públicas, el acceso a niveles de formación posgradual y la conformación de programas de formación pedagógica y disciplinar permanente en alianza desde la Secretaría de Educación y las Universidades de la Región en Antioquia y Colombia.

Palabras clave: Educación Física, Deporte Escolar, Políticas Públicas, Formación pedagógica y disciplinar permanente.
\end{abstract}

Abstract: The present paper is part of the investigation. It aimed to identify and describe the status of sport and physical education in the town of Medellin from the assessments of teachers attending basic primary education in the town of Medellin, for which he used the quantitative approach from one study experimental descriptive, where 140 teachers from public and private educational institutions participated Medellin. Its main contributions are in the context of educational institutions and sports training, defining routes for improvement for both scenarios from complementary dimensions in policies, infrastructure, ongoing teacher training and discipline for professionals that serve the area and their extracurricular activities. It is striking that only $26.4 \%$ of teachers serving in primary area have specific training in Physical Education, Recreation and Sports, none of the participating teachers have doctoral degrees, only $26.4 \%$ of teachers Basic Elementary have exclusive Physical Education, Recreation and Sport dedication, among other findings. This entails a development path for the teaching and discipline of teachers of Physical Education, Recreation and Sports Primary Basic that must be addressed from the design of public policies, access to training posgradual levels, the establishment of teacher training programs discipline and permanent alliance from the Ministry of Education and the universities of the region in Antioquia and Colombia.

Keywords: Physical Education, School Sport, Public Policy, Pedagogic formation and discipline permanent.

\section{Introducción}

Desde Políticas Públicas que orientan la legislación educativa y deportiva de Colombia, se encuentran aportes desde: Ley General de Educación (Ministerio de Educación Nacional, 1994), Ley 934 de diciembre 30 de 2004, (Ministerio de Educación Nacional, 2004), Ley 181 de enero 18 de 1995 o Ley del deporte (Coldeportes Nacional, 2001) y el Plan Decenal del Deporte (en adelante PDD) de (2009), entre otras, donde se resalta que hay lineamientos que buscan un cambio en el discurso fragmentado, sectoricista y protagonista del sector ${ }^{2}$, hacia una mirada integradora, determinante en los procesos de orientación del gasto en el recurso público, de pertinencia hacia la equidad y la inclusión social de diferentes proyectos que aporten al desarrollo humano, la convivencia y la Paz en Colombia, es en sí, una oportunidad

Dirección para correspondencia [Correspodence address]: Enoc Valentín González Palacio. E-mail: enoc.gonzalez@usbmed.edu.co para continuar posicionando un cambio epistemológico, conceptual, procedimental y actitudinal; De igual manera se debe destacar que el PDD es un plan indicativo, pues no cuenta con herramientas legales que hagan que se aborden sus directrices de manera obligatoria en cada departamento, sin embargo, con ello, se abren orientaciones de articulación para todo el ciclo estudiantil desde programas para el buen uso y aprovechamiento del tiempo libre, reflejados en proce-

1 La investigación "Situación actual del deporte y la educación física escolar en la ciudad de Medellín” fue realizada por el Instituto Municipal de Deportes y Recreación (INDER Medellín) y el grupo de investigación ESINED (Estudios Interdisciplinarios sobre Educación) en su línea Educación Física, Cuerpo y Motricidad de la Universidad de San Buenaventura Medellín.

2 Se entiende en los planteamientos del Plan Decenal del Deporte, la noción de sector los componentes de Deporte, Recreación, Educación Física y Actividad Física en el componente estudiantil y comunitario, abarcando así instancias y diferentes manifestaciones de cada subcomponente en el orden local, distrital, departamental, regional y nacional. 
sos desde el sector escolar básico hasta el nivel universitario, como escenario para la formación y la competición, detectando talentos, generando acciones promotoras de salud y la creación estratégica de las reservas que en el sector favorecen la competición y los altos logros en el País.

En sí, se reconocen espacios y escenarios para que las Instituciones Educativas y los entes deportivos del sistema nacional del deporte, realicen desde la actividad física, el deporte, la educación física y la recreación, diferentes acciones que favorezcan la democracia, la formación integral y la promoción de hábitos y estilos de vida saludables, de tal forma que se beneficien las comunidades con procesos de participación social, con criterios de equidad e inclusión en la implementación de las citadas políticas, es en definitiva, una apuesta para el próximo decenio en la perspectiva del desarrollo humano, la convivencia y la Paz en Colombia.

Esta reflexión crítica de los procesos de desarrollo que se tienen en el campo de conocimiento de la Educación Física y sus áreas de Educación Física Escolar y Deporte Formativo, se ven en diálogo y congruencia con planteamientos de Grau, M., \& Soler, S. (2003), quiénes invitan a tener presente por parte de profesores la importancia de la formación en valores en la Escuela, específicamente desde la Educación Física Escolar, acción que es vital si se cuenta con profesores comprometidos, formados e implicados en los procesos formativos de las generaciones futuras. En igual sintonía, se encuentra Sanmartín, M. G. (2004) quién plantea que los valores son determinantes en la formación integral del ser humano, para lo cual hace un reclamo para la promoción de los planes formativos y deportivos desde la Educación Física Escolar, invitando a la puesta en práctica de propuestas encaminadas al desarrollo de la práctica físico-deportiva y los estilos de vida saludables desde tempranas edades.

Para Santos Muñoz, S. (2005) su interés está en promover con los profesores de Educación Física Escolar una revisión de estudios que se ocupan de la formación, promoción, prevención, tratamiento y mejora de hábitos y estilos de vida saludable que resista ante las problemáticas epidemiológicas de obesidad y sobrepeso, acción que estaría en la línea de atención y formación pedagógica y disciplinaria que hoy ameritan los docentes del campo, para que se puedan adaptar a las circunstancias, inquietudes y problemas de la sociedad en que se encuentran inmersos.

Por otra parte, Castro Girona, M. J., Piéron, M., \& González Valeiro, M. (2006) apoyados en el paradigma de procesos mediadores, resaltan la actitud y la motivación de niños y niñas en las clases de Educación Física Escolar, donde la implicación del profesorado es de vital importancia en la presentación, desarrollo y evaluación de los contenidos presentados.

En la línea de generar espacios de desarrollo para la Educación Física Escolar desde un factor nuclear como es la acti- tud en el profesorado que la imparte, se encuentra también la propuesta de Berenguí Gil, R. \& Garcés de Los Fayos Ruíz, E. J. (2007) quiénes plantean que los valores, actitudes y normas para responder al fomento del deporte escolar en forma positiva, se gestan desde la responsabilidad pública del profesorado, potenciando el valor social del hecho o acto deportivo ejecutado en el contexto de las Escuelas.

Para Díaz Suárez, A. (2007), la Educación Física Escolar y el Deporte, constituyen uno de los fenómenos más importantes que rigen y articulan la vida cotidiana de un País y sus ciudadanos, invitando a que sea desarrollada por especialistas para hacer posible la calidad educativa, resignificar la asignatura escolar y equipararla ante otras disciplinas en las culturas que hoy habitamos.

Con Moreno Murcia, J. A., Alonso Villodre, N., Martínez Galindo, C. \& Cervello Gimeno, E. (2005) se ubica la motivación, la disciplina y la satisfacción en la frecuencia de las prácticas deportivas escolares, ello los implica y los orienta hacia la consecución y ejecución de las tareas en sus clases, factor determinante para las responsabilidades de motivación que debe liderar el profesorado. En esa misma ruta existen aportes de Moreno Murcia, J. A. \& Cervello Gimeno, E. (2009), quiénes continúan haciendo hincapié en el carácter del educador en los procesos de formación deportiva en las clases de Educación Física, donde el pensamiento del alumnado será determinado por lo que hace el profesorado como exponente de elementos democráticos, alegres, bondades, justicia, comprensión y agrado en relación con la práctica deportiva escolar.

Cecchini Estrada, J. A., González González-Mesa, C., Méndez Giménez, A., Fernández-Río, J., Contreras Jordán, O. \& Romero Granados, S. (2008) invitan a tener presente metas sociales en las intenciones de la formación y la práctica deportiva de los estudiantes en las clases de Educación Física, ante lo cual las intenciones futuras de práctica del deporte se pueden ver afectadas o promovidas en la vida futura de los mismos.

Se puede inferir inicialmente, una preocupación de investigadores del campo de conocimiento de la educación física, específicamente hacia su área de educación física y deporte escolar, para repensar y resignificar la formación pedagógica y disciplinar del profesorado desde una mirada integral, permanente, continua y continuada hacia la especialización o bien llamada formación posgradual, preferiblemente doctoral, integradora de las políticas de desarrollo del campo en sus áreas en los Países e integrada a los avances en infraestructura física y administrativa según los contextos de la sociedad actual.

En esa ruta de análisis crítico, el presente proyecto se orienta por responder a la cuestión de: ¿Cuál es la situación actual del deporte y la educación física escolar en el municipio de Medellín? Ante lo cual, se diseñó como objetivo Ge- 
neral: Describir la situación actual del deporte y la educación física escolar en el municipio de Medellín a partir de las apreciaciones de los docentes que atienden la básica primaria en el municipio de Medellín, y Específicos: Identificar las manifestaciones del deporte escolar y la educación física en las instituciones de básica primaria del Municipio de Medellín. Describir las manifestaciones deportivas extraescolares que promuevan las instituciones educativas del municipio de Medellín. Ofrecer elementos conceptuales y metodológicos que apoyen la toma de decisiones y cambios en la dinámica y funcionamiento del deporte y la educación física escolar para del el municipio de Medellín.

Por lo anterior, el proyecto se orientó principalmente desde núcleos temáticos como son: Educación Física Escolar y Deporte Escolar. En la educación física, la recreación y el deporte desde el contexto escolar, se generó una ruta para su comprensión desde directrices internacionales con Gil-Madrona, Contreras Jornan, Gómez Víllora, \& Gómez Barreto (2008), desde perspectivas nacionales con el Ministerio de Educación Nacional (2004), Bonilla Baquero (1996) y Camacho Coy (2003), desde una mirada local y regional por los aportes de profesores, instituciones y grupos de investigación: Gobernación de Antioquia-Instituto Universitario de Educación Física (2009), Grupo de Cultura Somática (2010), Padierna Cardona, J. C., \& González Palacio, E. V. (2013), Padierna Cardona, J. C., González Palacio, E. V. \& Cardona Mejía, L.M. (2015), donde la educación física, concebida como pedagogía de la motricidad por su carácter formativo y educativo, implica tener adecuados fundamentos actitudinales, procedimentales y conceptuales para comprender la educación física como acción dinámica, biológica, política, social y cultural; principalmente, desde la corporeidad y la motricidad, donde las capacidades perceptivo motrices, físico motrices y socio motrices, en asocio con las dimensiones del medio ambiente, educación sexual y promoción de la salud, van aportando al desempeńo adecuado y estructurado en diferentes expresiones motrices, acciones que deben ser desarrolladas desde perspectivas dinámicas, abiertas, experienciales y vivenciales, pues la metodología experiencial brinda oportunidades de ser implementada con éxito en el contexto escolar.

En este sentido, el grupo de investigadores espera que el profesor del área de educación física, recreación y deporte, sea un conocedor y provocador de las expresiones motrices (de autoconocimiento, deportivas, lúdicas, recreativas, rítmicas, artísticas, cotidianas, entre otras), a las que pueden acceder los actores del proceso educativo en una acción compartida y flexible que propenda por el logro de las competencias planteadas por Chaverra Fernández, B., Gaviria Cortés, D., González Palacio, E.V., Uribe Pareja, I.D., Díaz Leal, J.B, Padierna Cardona, J.C., Martínez Ardila, J.D. \& Bustamante Castaño, S.A. en la Guía de Estándares Básicos de Competencia para el Área de Educación Física, Recreación y Deporte en el Departamento de Antioquia (2011) de INDEPORTES, para aportar al desarrollo humano integral desde estrategias integradoras que generen adecuadas acciones de pensamiento y generación de conocimiento a través de procesos conceptuales, procedimentales, actitudinales y transversales (Padierna Cardona, 2010), reflejando las relaciones de la educación física con el campo cultural y social en lo escolar y extraescolar.

En el núcleo temático de deporte escolar, se pretendió entender conceptual y contextualmente las implicaciones de una postura a tomar, dadas las múltiples connotaciones que el término recibe en diferentes contextos, para ello, se partió inicialmente de los aportes de Elias y Dunning (1992), Blázquez (1995), Devís (1995), Díaz Suárez \& Martínez Moreno (2003), López Parralo (2006), Rodriguez Castellón (2010), Bustamante, Chaverra y González Palacio (2011), puntualizando: el deporte en términos de lo escolar, atiende a la lógica del aprendizaje del propio deporte, pero sobre todo como un medio que posibilita la adquisición de diferentes elementos propios de la cultura, su intensión está dada por lo cognitivo, procedimental, conceptual y actitudinal, y desborda los límites de la escuela como espacio físico y se apuntala en el ámbito de los requerimientos sociales y formativos.

\section{Método}

El estudio utilizó la metodología cuantitativa, siendo un estudio no experimental donde no se manipularon variables independientes. Específicamente es una investigación descriptiva (Polit y Hungler, 2000), dado que pretendió identificar y describir tendencias y apreciaciones acerca del estado actual del deporte y la Educación Física escolar, principalmente, de la voz y opinión de los docentes encargados de la Básica Primaria en la ciudad de Medellín. La inclusión de la metodología cuantitativa se dio por la necesidad de describir las principales variables en términos de las prácticas y percepciones frente al deporte y la Educación Física escolar y extraescolar. Además, la indagación se realizó de manera estadísticamente representativa en lo referente a la población docente que atiende el Área de Educación Física, Recreación y Deporte en la Básica Primaria.

La unidad de muestreo fueron las Instituciones Educativas de Medellín, que ofrecieran los niveles de primaria y como unidad de análisis se tuvo en cuenta a los profesores de estas instituciones que atendieran el área de Educación Física Recreación y Deportes, el universo entonces lo constituyen profesores de las 338 Instituciones Educativas del municipio de Medellín; 214 (63,3\%) del sector público y 124 (36,7\%) del sector privado. Se realizó un muestreo probabilístico estratificado (Grisales, 2000), teniendo como principales estratos el tipo de Institución Educativa y las Comunas de Medellín, donde se encuestó por lo menos a un docente de cada institución de la Básica Primaria. Los criterios de cálculo de 
la muestra fueron los siguientes:

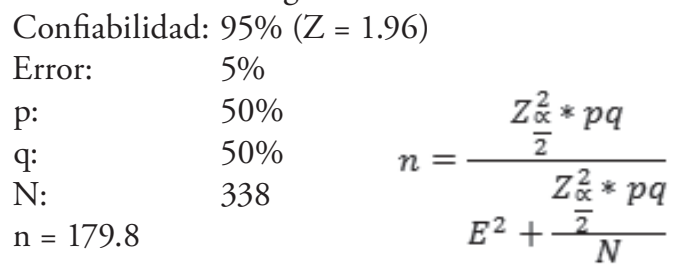

El tamaño inicial de la muestra es de 179,8 docentes, pero dado que este valor es mayor al $10 \%$ de la población, se utilizó el procedimiento de ajuste de la muestra (ñ) (Grisales, 2000) para encontrar el valor final de la misma. El procedimiento fue como sigue a continuación:

$$
n=\frac{n}{1+n / N}
$$

Al realizar este ajuste, se obtuvo como muestra final 117 docentes. Y al finalizar el trabajo de campo, se recogió información en las 117 instituciones establecidas, se indagó a un total de 140 docentes, se agruparon en grupos etarios: entre $31 \mathrm{y}$ 40 años (36,4\%), entre 41 y 50 años (33,6\%), entre 20 y 30 años $(19,3 \%)$ y más de 50 años $(10,7 \%)$.

Como Instrumento para la recolección de información se utilizó una "encuesta descriptiva" (Briones, 1986, p. 50), en cuyo cuestionario prevalecieron las preguntas cerradas o estructuradas (selección múltiple con única respuesta y con varias alternativas), sobre variables de naturaleza cualitativa, es decir nominales (categóricas) y ordinales (escalas tipo Likert), que recogieron datos sobre aspectos demográficos, socioeconómicos, opiniones y actitudes (1986, p. 49) frente a la clase de educación física y el deporte al interior y fuera de la escuela; las pocas preguntas abiertas o no estructuradas que se realizaron, se hicieron con el fin de solicitar razones acerca del porqué de una respuesta anterior, estas preguntas se categorizaron con el fin de obtener tendencias en los testimonios ofrecidos, los cuales se utilizaron para ilustrar y complementar algunos datos estadísticos.

Para el análisis de la información, los datos fueron digitados y procesados en Excel 2010, y el análisis estadístico se realizó en el programa SPSS V20. Para los datos descriptivos (univariado) se utilizó, principalmente, la moda y la media. Para el análisis bivariado se recurrió como principal estadístico a la prueba chi-cuadrado.

Ya en perspectiva de complemento al proceso de diseño de la investigación se había diseñado el planteamiento del problema, reconociendo fundamentos legales, formativos y contextuales, dado que el área de educación física, recreación y deportes en Colombia, es pensada en términos de beneficios académicos, para la salud, el deporte y otras dimensiones que desde las políticas internas del País, hacen posible su abordaje en los grados escolares, no obstante, su estado actual y situa- ción solo es conocida por aquellos directivos que la orientan, los docentes que la atienden, los estudiantes que la reciben, sin embargo, este conocimiento es fragmentado en términos de ciudad en Medellín, su conocimiento se restringe a una serie de comentarios particulares que sólo invitan a indagar efectivamente lo que pasa.

\section{Resultados}

Se presenta a continuación, la caracterización del deporte escolar y la educación física en las instituciones de básica primaria de Medellín, para efectos de la presente publicación.

La indagación a los docentes de la Básica Primaria se realizó en el siguiente tipo de instituciones: $66,4 \%$ de naturaleza pública y $33,6 \%$ de privada.

Figura 1. Tipo de Institución Educativa.

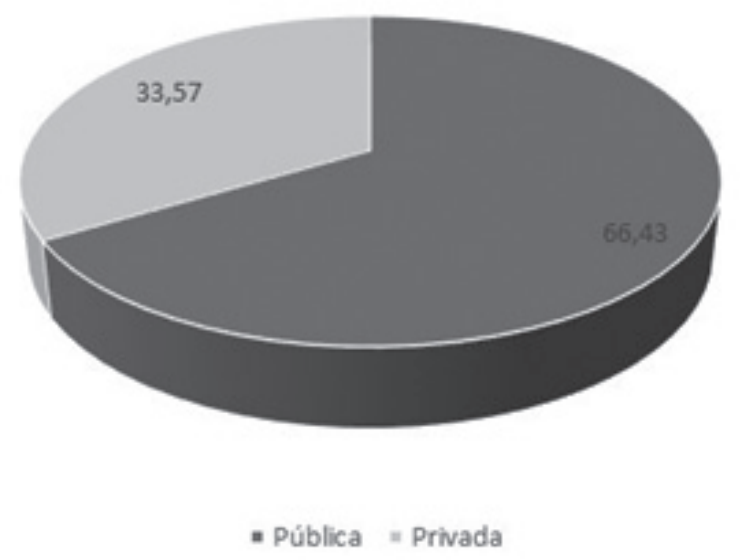

Con respecto al perfil académico de los docentes, se encontró que solo un $65,7 \%$ tienen formación a nivel de pregrado; no obstante, debe precisarse que solo un $26,4 \%$ de los docentes que atienden el área en Primaria tienen formación específica en Educación Física, Recreación y Deporte. Ello muestra un panorama poco disciplinar a la hora de impartir el área y evidencia la necesidad de implementar acciones institucionales para mejorar la situación. Debe destacarse que existe una asociación estadística encontrada a partir de la aplicación de chicuadrado $\left(\chi^{2}\right)$, donde $\mathrm{p}=0.000$, lo que indica que el tipo de institución está asociado al tipo de formación que tienen los docentes desempeñados en la Básica Primaria en Educación Física, Recreación y Deporte. En las instituciones privadas es más probable encontrar docentes con formación en el área; en las instituciones públicas es más probable que los docentes tengan formación en otras áreas. 
Figura 2. Formación en pregrado.

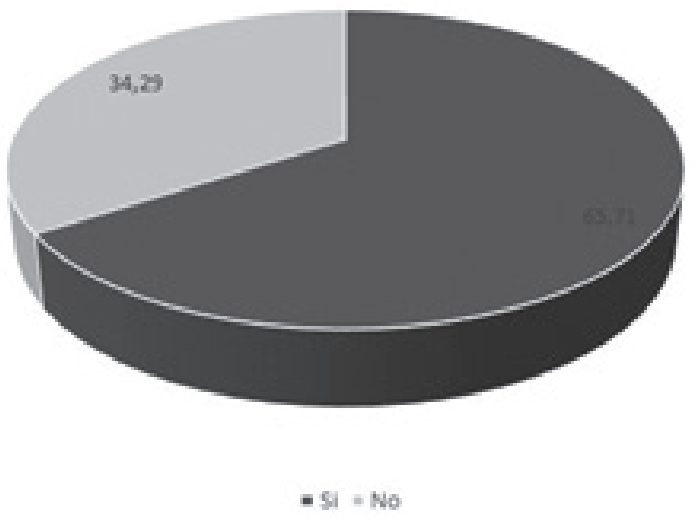

Figura 3. Relación de formación con el Área de Educación Física, Recreación y Deporte.

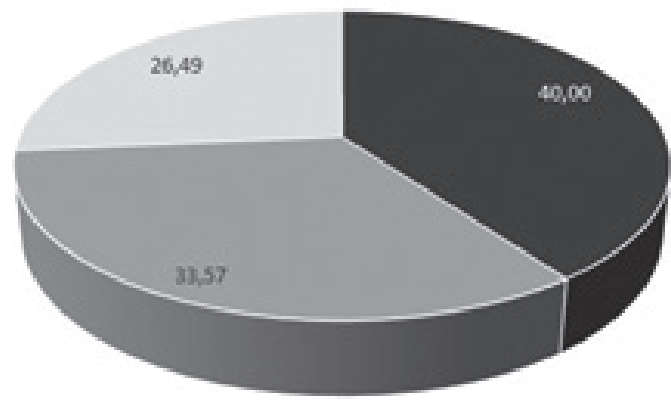

- No a No aplica is

Tabla 1. Relación entre el tipo de institución y el título del Área de Educación Física, Recreación y Deporte.

\begin{tabular}{|c|c|c|c|c|c|c|}
\hline & & & \multicolumn{3}{|c|}{ TÍTULO DEL ÁREA DE EF-R-D } & \multirow{2}{*}{ Total } \\
\hline & & & No & No aplica & Sí & \\
\hline \multirow{4}{*}{ TIPO DE INSTITUCIÓN } & \multirow{2}{*}{ Privada } & Recuento & 6 & 10 & 31 & 47 \\
\hline & & \% título del área de EF-R-D & $10,7 \%$ & $21,3 \%$ & $83,8 \%$ & $33,6 \%$ \\
\hline & \multirow{2}{*}{ Pública } & Recuento & 50 & 37 & 6 & 93 \\
\hline & & \% título del área de EF-R-D & $89,3 \%$ & $78,7 \%$ & $16,2 \%$ & $66,4 \%$ \\
\hline \multirow{2}{*}{ Total } & & Recuento & 56 & 47 & 37 & 140 \\
\hline & & \% título del área de EF-R-D & $100,0 \%$ & $100,0 \%$ & $100,0 \%$ & $100,0 \%$ \\
\hline
\end{tabular}

Al indagar sobre la formación de posgrado, se encontró que el $35,7 \%$ de los docentes poseen especialización, aunque debe hacerse la salvedad de que la mayoría de los campos de formación no son en Educación Física. Con respecto a la maestría, solo la han estudiado un 2,9\% de los docentes, y únicamente dos son del área. Ningún docente posee título de doctor. Estos datos muestran que el área no es atendida por docentes con formación específica, sino por aquel que atiende el grado de Primaria asignado, e indica la necesidad de implementar acciones de capacitación específica o mayor vinculación de personal del área.

Figura 4. Formación en posgrado especialización.

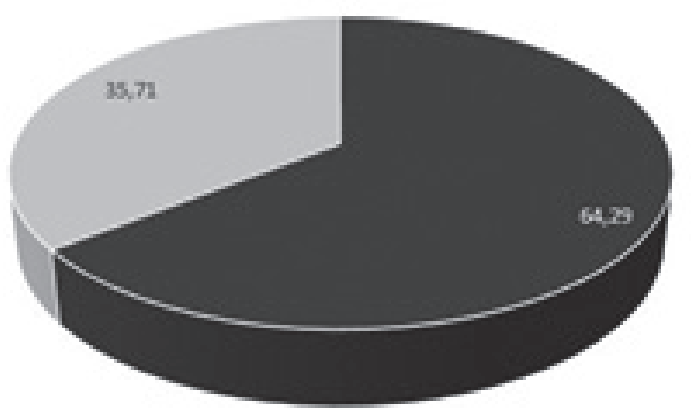

- 51 * No
Figura 5. Formación en posgrado maestría.

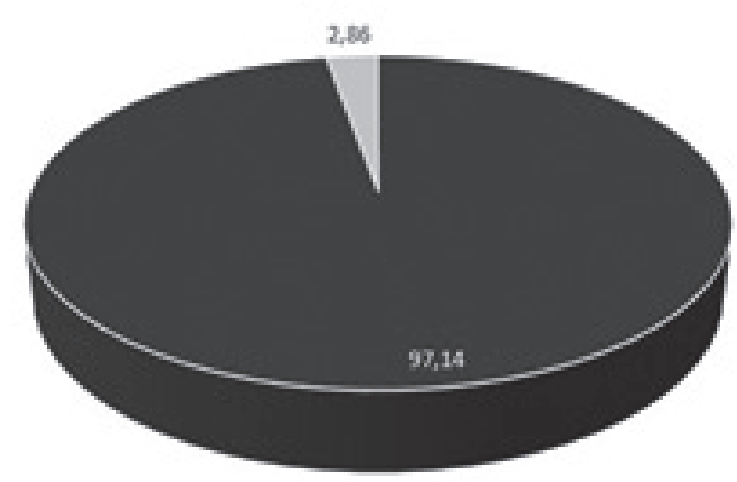

* No * 51

Con respecto al tipo de contrato, la mayoría de los docentes demuestran estabilidad laboral, pues poseen contrato a término indefinido (57,9\%). Los otros cuentan con una contratación no vinculada; la más común es la definida (35,7 \%). 
Figura 6. Tipo de contrato de los docentes.

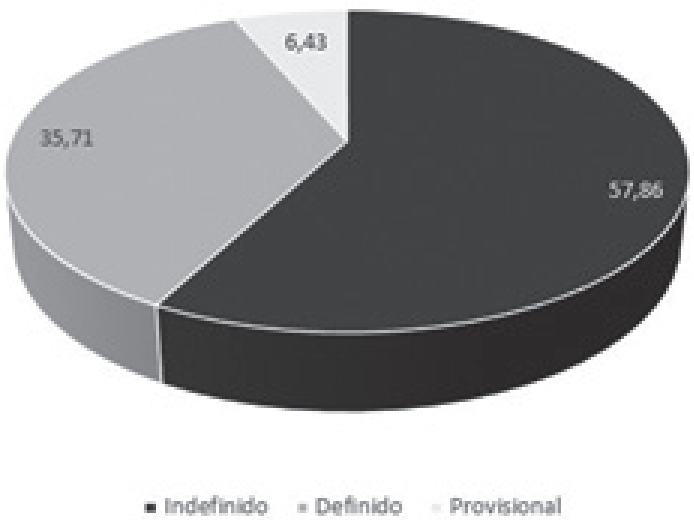

Numerosos docentes enseñan en varios grados de Básica Primaria. Los grados más recurrentes son primero $(39,3 \%)$ y cuarto $(42,1 \%)$.

Figura 7. Grados en los que se desempeñan los docentes de Básica Primaria.

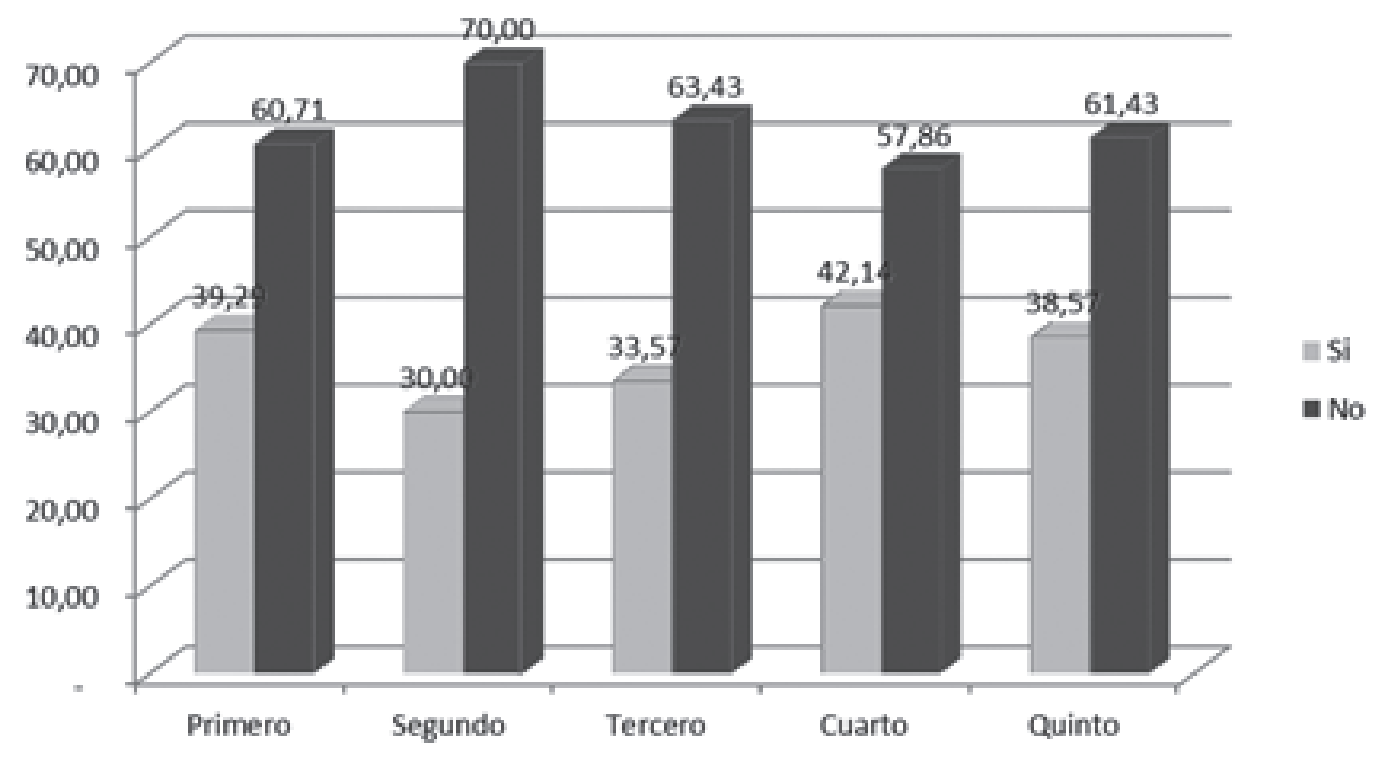

$\mathrm{Al}$ atender a la relación de los docentes y las áreas, se observó que la mayoría de docentes $(45,7 \%)$ ofrecen todos las áreas en su grupo, incluyendo la Educación Física; solo un 26,4 \% de los docentes de Básica Primaria tienen dedicación exclusiva a Educación Física, recreación y deporte. Se asoció esta variable con el tipo de institución y se evidenció que mientras los docentes de la Básica Primaria en las IE públicas atienden el área al mismo tiempo que otras áreas, las instituciones privadas cuentan con un docente con dedicación exclusiva a la Educación Física (89,2 \%). Este dato es estadísticamente representativo, pues el valor de $\mathrm{p}\left(\chi^{2}\right)$ es de 0.000 , lo que significa una asociación estadística entre el tipo de institución y las áreas que son atendidas por los docentes. En pocas palabras, la Educación Física se encuentra relacionada con el tipo de institución y las instituciones privadas son las que presentan mayor favorabilidad a la hora de impartir.
Figura 8. Áreas atendidas por los docentes.

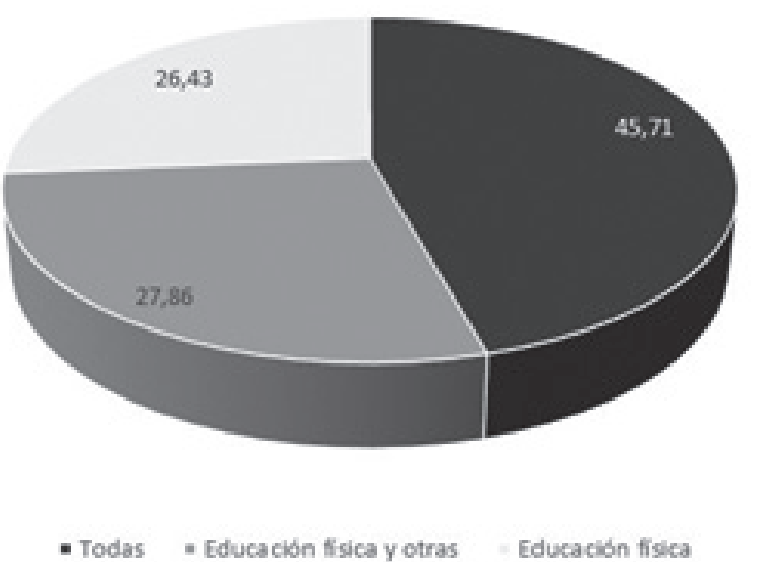


Tabla 5. Relación entre las áreas dictadas por los docentes y el tipo de institución.

\begin{tabular}{|c|c|c|c|c|c|c|}
\hline & & & \multicolumn{3}{|c|}{ ÁREAS DICTADAS POR EL DOCENTE } & \multirow{2}{*}{ Total } \\
\hline & & & Educación Física & Educación Física y / o otras & Todas & \\
\hline \multirow{4}{*}{ TIPO DE INSTITUCIÓN } & \multirow{2}{*}{ Privada } & Recuento & 33 & 5 & 9 & 47 \\
\hline & & $\%$ áreas dictadas & $89,2 \%$ & $12,8 \%$ & $14,1 \%$ & $33,6 \%$ \\
\hline & \multirow{2}{*}{ Pública } & Recuento & 4 & 34 & 55 & 93 \\
\hline & & $\%$ áreas dictadas & $10,8 \%$ & $87,2 \%$ & $85,9 \%$ & $66,4 \%$ \\
\hline \multirow{2}{*}{ Total } & & Recuento & 37 & 39 & 64 & 140 \\
\hline & & $\%$ áreas dictadas & $100,0 \%$ & $100,0 \%$ & $100,0 \%$ & $100,0 \%$ \\
\hline
\end{tabular}

Además, se indagó por el ofrecimiento del Área de Educación Física, Recreación y Deporte en las IE y se encontró que el $1,4 \%$ de ellas no la ofrece (porcentaje correspondiente a dos instituciones públicas). Aunque es una cifra muy baja, debe de todas maneras resaltarse, pues la Educación Física es por Ley 115 de 1994 un área fundamental y obligatoria.

Figura 9. Ofrecimiento del Área de Educación Física, Recreación y Deporte de IE.

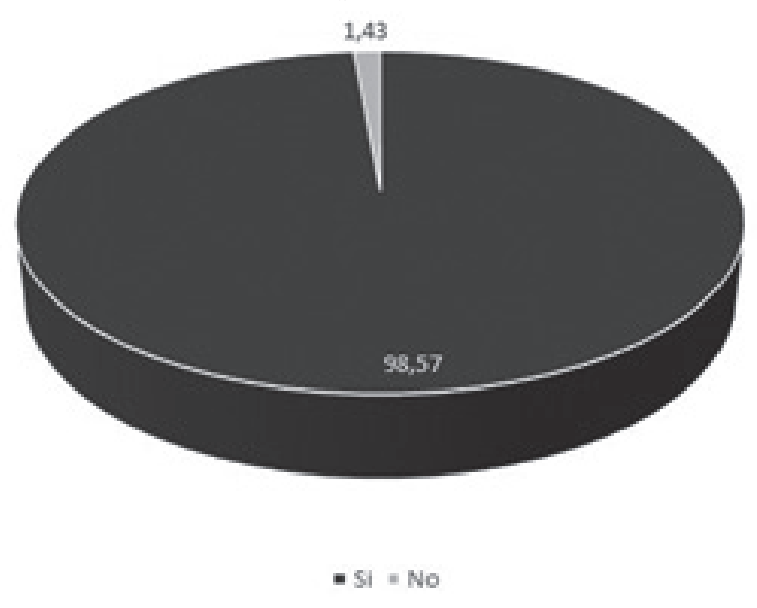

La indagación sobre el número de horas que se dicta la Educación Física arrojó que la moda es de 2 horas a la semana y el promedio es de 2,26; respecto al número de sesiones por semana, la moda también es de 2 y el promedio es de 1,87 . La Ley 115 de 1994 dispone que las IE son las encargadas de la planeación de las áreas y cursos; sin embargo, este dato indica que la Educación Física en la escuela no es el área que más asignación horaria posee. Lo anterior puede tener implicaciones en los beneficios a la población infantil en términos físicos, psicológicos y sociales.

Con respecto a la planeación del área, el 82,1 \% de los docentes manifiestan que las IE cuentan con proyecto integral de área (PIA). Aunque es un porcentaje alto, el asunto es desalentador pues todas las instituciones deberían tener estruc- turado su PIA del área. Este punto no se cumple en el 17,9 $\%$ de las instituciones, equivalente a 25 IE, de las cuales un $92 \%$ son públicas; es decir, la carencia de PIA es más común en la Básica Primaria pública que en la privada. Esta asociación tiene, de hecho, un valor estadísticamente representativo, pues el valor de $\mathrm{p}\left(\chi^{2}\right)$ es de 0.003 . La indagación también incluyó la forma de estructuración de los PIA: la más común es a partir de mallas curriculares (40,7\%), seguido de unidades didácticas $(32,1 \%)$.

Figura 10. Presencia del plan integral de área (PIA) en las instituciones.

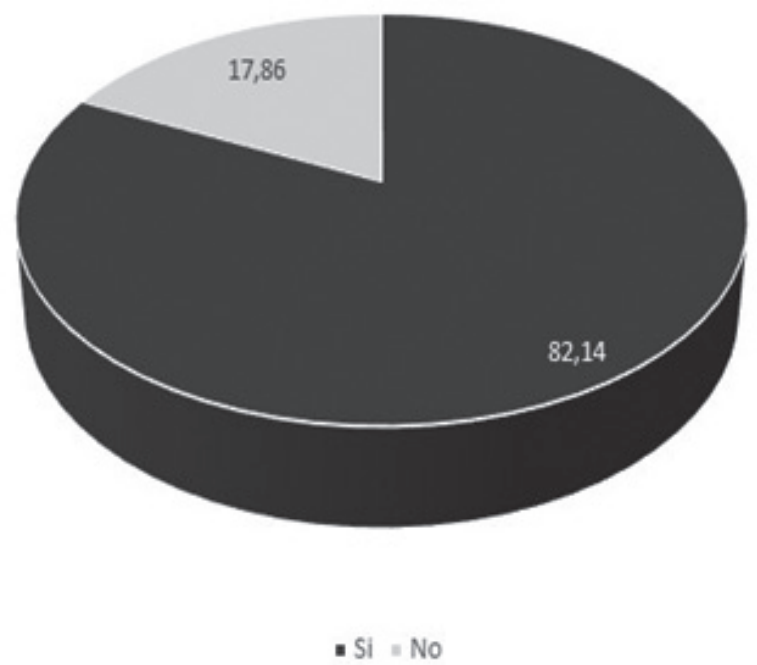

En términos de planeación, se indagó si los docentes utilizan algún modelo para abordar el área y se encontró que un $80 \%$ síl lo poseen. Del $20 \%$ de docentes que no lo poseen (equivalente a 28 docentes), 96,4\% son de instituciones educativas públicas (27 docentes). Según lo anterior, en la utilización de un modelo de planeación para la clase de Educación Física también hay asociación estadística con el tipo de institución, siendo poco frecuente en las instituciones privadas y más común en las públicas $\left(\chi^{2}, \mathrm{p}=0.000\right)$. 
Figura 11. Utilización de modelo de planeación en la clase de Educación Física, Recreación y Deporte.

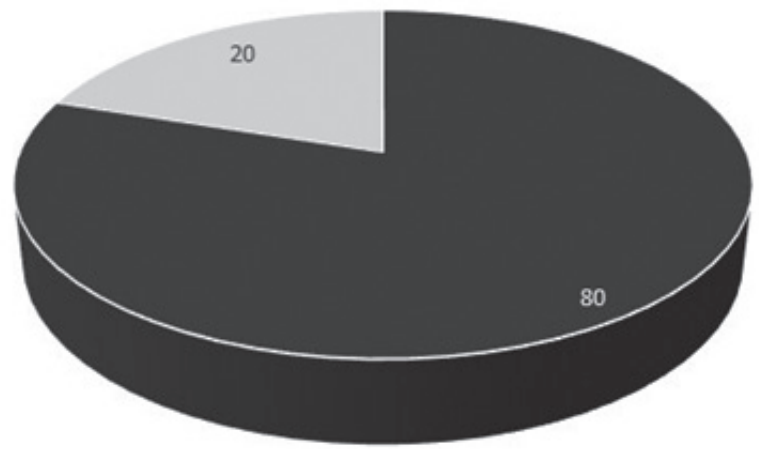

- Si $=$ No

Tabla 3. Relación entre la utilización de un modelo de planeación en Educación Física y el tipo de institución.

\begin{tabular}{|c|c|c|c|c|c|}
\hline & & & \multicolumn{2}{|c|}{ UTILIZACIÓN MODELO DE PLANEACIÓN } & \multirow[t]{2}{*}{ Total } \\
\hline & & & No & Sí & \\
\hline \multirow{4}{*}{ TIPO DE INSTITUCIÓN } & \multirow{2}{*}{ Privada } & Recuento & 1 & 46 & 47 \\
\hline & & $\%$ modelo de planeación & $3,6 \%$ & $41,1 \%$ & $33,6 \%$ \\
\hline & \multirow{2}{*}{ Pública } & Recuento & 27 & 66 & 93 \\
\hline & & $\%$ modelo de planeación & $96,4 \%$ & $58,9 \%$ & $66,4 \%$ \\
\hline \multirow{2}{*}{ Total } & & Recuento & 28 & 112 & 140 \\
\hline & & $\%$ modelo de planeación & $100,0 \%$ & $100,0 \%$ & $100,0 \%$ \\
\hline
\end{tabular}

Respecto también al tema de planeación, se preguntó por los tipos de contenidos abordados en la clase de Educación Física, Recreación y Deporte. Se halló coherencia entre los contenidos de los lineamientos curriculares, las orientaciones pedagógicas del Ministerio de Educación y los estándares básicos de competencia de la Secretaría de Educación para la Cultura de Antioquia. Entre los contenidos que mencionan los docentes están las habilidades motrices básicas, los deportes de base como el atletismo y la gimnasia, y diferentes elementos perceptivo-motrices (Castañer y Camerino, 1991) tales como el ritmo, la estructuración espacio-temporal, entre otros. Sin embargo, no hay una unidad de criterios en su abordaje por grados, los contenidos aparecen indistintamente de primero a quinto.

Además, cuando se solicita describir o explicar el modelo de planeación, muy pocos docentes aducen una estructura didáctica dividida por componentes (parte inicial, central y final) o elementos didácticos (problema, objetivos, contenidos, métodos, forma, medios y recursos, evaluación, entre otros). En cambio, aparecen elementos aislados que no dan cuenta de una estructura, sino más bien de una de sus partes, como por ejemplo: indicadores, logros, etapas de desarrollo, entre otros. Estos elementos de planeación muestran que los docentes conocen algunos aspectos del área, pero falta precisar elementos conceptuales y metodológicos.

Los docentes se ayudan de diferentes fuentes para el proceso de planeación en el Área de Educación Física, Recreación y Deporte. La principal fuente de consulta son los PIA (35\%), seguido de los lineamientos curriculares $(30 \%)$ y de la documentación sobre competencias $(16,4 \%)$, ya sean las emanadas por el Ministerio de Educación Nacional (Orientaciones pedagógicas, con 9,3\%) o por la Secretaría de Educación para la Cultura de Antioquia (Estándares básicos de competencia, con $7,1 \%)$.

Figura 12. Fuentes de planeación. 


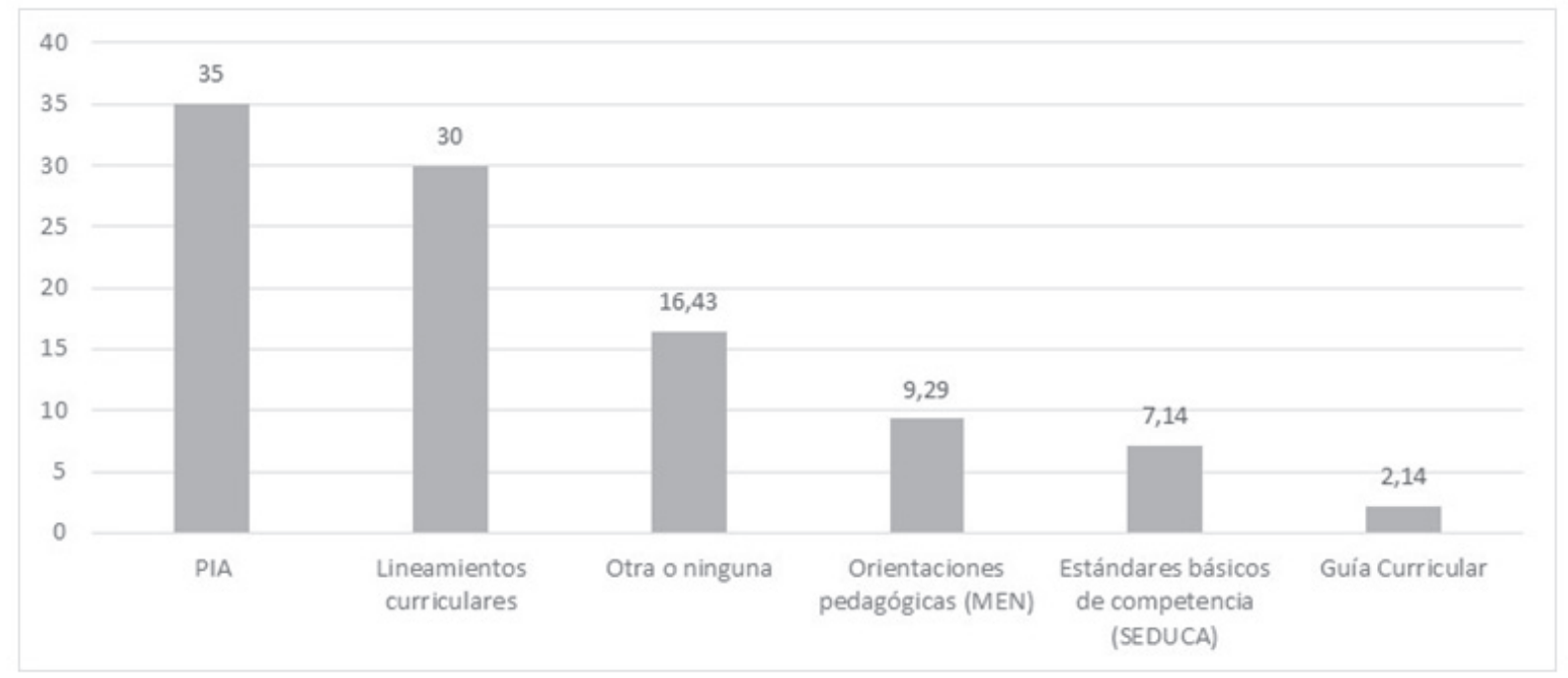

Así mismo, se indagó sobre las principales manifestaciones deportivas, lúdicas y recreativas en las IE. Se encontró que los niños de Básica Primaria prefieren las actividades de naturaleza deportiva, con un 76,4\%. El 41,43\% prefieren el fútbol o microfútbol; el baloncesto también es mencionado, pero con menos frecuencia. Debe destacarse que esta tendencia se ve en muchas instituciones en la forma de campeonatos o juegos interclases.

Con respecto a lo lúdico-recreativo, son los juegos tradicionales, los juegos con lasos o cuerdas, y las rondas lo que se presenta en la Básica Primaria.

Figura 13. Manifestaciones lúdicas, recreativas y deportivas en la Básica Primaria.

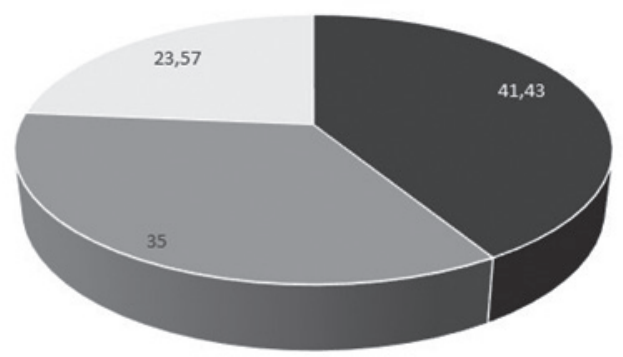

- Manifestación lúdico recreativa = Fútbol-microfútbol Manifestación deportiva
Con el fin de obtener un panorama general del Área de Educación Física, Recreación y Deporte en la Básica Primaria, se indagó sobre seis variables referidas a esta, tales como percepción general frente al área, percepción general de la IE, cantidad y calidad de los espacios, y cantidad y calidad de los materiales. Para la indagación de estas variables se utilizaron preguntas tipo Likert, con cinco opciones, las cuales se recategorizaron en tres para poder establecer relaciones con el tipo de institución.

La percepción general que los docentes tienen frente al Área de Educación Física, Recreación y Deporte en la Básica Primaria es positiva (92,9\%), por lo que reconocen su importancia en esta etapa escolar. Es de aclarar que esta percepción no presentó asociación estadística con respecto al tipo de institución $\left(\chi^{2}, \mathrm{p}=0.580\right)$; es decir, independientemente del tipo de institución en la que se desempeńe el docente, la percepción frente al área en la Básica Primaria es positiva.

Las percepciones sobre el área que tiene la IE se inclinaron nuevamente hacia lo positivo, tanto en las públicas (55,6 \%) como en las privadas (44,4\%). No obstante, aparecieron en las instituciones públicas, sobre todo, percepciones negativas $(91,7 \%)$ y aceptables $(93,1 \%)$, diferencias estadísticamente significativas $\left(\chi^{2}, \mathrm{p}=0.000\right)$. 
Tabla 4. Relación entre la percepción de Educación Física en la Básica Primaria ofrecida en la IE y el tipo de institución.

\begin{tabular}{|c|c|c|c|c|c|c|}
\hline & & & \multicolumn{3}{|c|}{$\begin{array}{c}\text { PERCEPCIÓN FRENTE A EF-R-D EN BÁSICA } \\
\text { PRIMARIA OFRECIDA EN IE }\end{array}$} & \multirow[t]{2}{*}{ Total } \\
\hline & & & Negativa & Aceptable & Positiva & \\
\hline \multirow{4}{*}{ TIPO DE INSTITUCIÓN } & \multirow{2}{*}{ Privada } & Recuento & 1 & 2 & 44 & 47 \\
\hline & & $\%$ percepción frente a EF-R-D & $8,3 \%$ & $6,9 \%$ & $44,4 \%$ & $33,6 \%$ \\
\hline & \multirow{2}{*}{ Pública } & Recuento & 11 & 27 & 55 & 93 \\
\hline & & $\%$ percepción frente a EF-R-D & $91,7 \%$ & $93,1 \%$ & $55,6 \%$ & $66,4 \%$ \\
\hline \multirow{2}{*}{ Total } & & Recuento & 12 & 29 & 99 & 140 \\
\hline & & $\%$ percepción frente a EF-R-D & $100,0 \%$ & $100,0 \%$ & $100,0 \%$ & $100,0 \%$ \\
\hline
\end{tabular}

Con respecto a la cantidad y calidad de los espacios, la indagación permitió establecer que la percepción depende del tipo de institución. El comportamiento es similar a la anterior variable, prevalece la calificación positiva, pero las calificaciones negativas y aceptables se acentúan más en las instituciones públicas que en las privadas. Estas diferencias son estadísticamente significativas (cantidad espacios, $\chi^{2}, \mathrm{p}=$ 0.002 y calidad de espacios, $\left.\chi^{2}, p=0.000\right)$.
Entre las razones que aducen los docentes para dar las calificaciones negativas o aceptables están los insuficientes espacios (cantidad), lo poco apropiados y el escaso mantenimiento, además de que estos carecen de medidas técnicas (calidad). En síntesis, como dice uno de los profesores: "No hay condiciones adecuadas".

Tabla 5. Relación entre la cantidad de espacios y el tipo de institución.

\begin{tabular}{|c|c|c|c|c|c|c|}
\hline & & & \multicolumn{3}{|c|}{$\begin{array}{c}\text { PERCEPCIÓN FRENTE A LA } \\
\text { CANTIDAD DE ESPACIOS EN LA IE }\end{array}$} & \multirow[t]{2}{*}{ Total } \\
\hline & & & Negativa & Aceptable & Positiva & \\
\hline \multirow{4}{*}{ TIPO DE INSTITUCIÓN } & \multirow{2}{*}{ Privada } & Recuento & 5 & 12 & 30 & 47 \\
\hline & & $\%$ percepción cantidad de espacios & $14,7 \%$ & $27,3 \%$ & $48,4 \%$ & $33,6 \%$ \\
\hline & \multirow{2}{*}{ Pública } & Recuento & 29 & 32 & 32 & 93 \\
\hline & & $\%$ percepción cantidad de espacios & $85,3 \%$ & $72,7 \%$ & $51,6 \%$ & $66,4 \%$ \\
\hline \multirow{2}{*}{ Total } & & Recuento & 34 & 44 & 62 & 140 \\
\hline & & \% percepción cantidad de espacios & $100,0 \%$ & $100,0 \%$ & $100,0 \%$ & $100,0 \%$ \\
\hline
\end{tabular}

Tabla 6. Relación ente la calidad de los espacios y el tipo de institución

\begin{tabular}{|c|c|c|c|c|c|c|}
\hline & & & \multicolumn{3}{|c|}{$\begin{array}{l}\text { PERCEPCIÓN FRENTE A LA CALIDAD } \\
\text { DE ESPACIOS EN LA IE }\end{array}$} & \multirow{2}{*}{ Total } \\
\hline & & & Negativa & Aceptable & Positiva & \\
\hline \multirow{4}{*}{ TIPO DE INSTITUCIÓN } & \multirow{2}{*}{ Privada } & Recuento & 1 & 12 & 34 & 47 \\
\hline & & $\%$ percepción calidad de espacios & $4,5 \%$ & $22,6 \%$ & $52,3 \%$ & $33,6 \%$ \\
\hline & \multirow{2}{*}{ Pública } & Recuento & 21 & 41 & 31 & 93 \\
\hline & & $\%$ percepción calidad de espacios & $95,5 \%$ & $77,4 \%$ & $47,7 \%$ & $66,4 \%$ \\
\hline \multirow{2}{*}{\multicolumn{2}{|c|}{ Total }} & Recuento & 22 & 53 & 65 & 140 \\
\hline & & $\%$ percepción calidad de espacios & $100,0 \%$ & $100,0 \%$ & $100,0 \%$ & $100,0 \%$ \\
\hline
\end{tabular}

Con respecto a los materiales, continúa la tendencia a una valoración positiva y se mantiene la asociación con respecto al tipo de institución frente a las valoraciones negativas y aceptables de las cantidades y calidades de los materiales. Los valores de $\mathrm{p}\left(\chi^{2}\right)$ son, respectivamente, 0.001 y 0.000 , lo que indica unas diferencias estadísticamente significativas, por lo que las apreciaciones negativas o simplemente aceptables frente a la cantidad de espacios y calidad de los mismos son una 
tendencia de las instituciones públicas. Los docentes dicen estar inconformes con las cantidades de materiales porque no son suficientes o son muy pocos para el número de estudiantes. Frente a la calidad, la principal razón de descontento es que los materiales están deteriorados o en mal estado. El siguiente testimonio sustenta, en general, esta realidad: "No son suficientes y se encuentran en mal estado".

Tabla 7. Relación entre la cantidad de materiales y el tipo de institución.

\begin{tabular}{|c|c|c|c|c|c|c|}
\hline & & & \multicolumn{3}{|c|}{$\begin{array}{c}\text { PERCEPCIÓN FRENTE A LA } \\
\text { CANTIDAD DE MATERIALES EN LA IE }\end{array}$} & \multirow{2}{*}{ Total } \\
\hline & & & Negativa & Aceptable & Positiva & \\
\hline \multirow{4}{*}{ TIPO DE INSTITUCIÓN } & \multirow{2}{*}{ Privada } & Recuento & 3 & 15 & 29 & 47 \\
\hline & & $\%$ percepción cantidad de materiales & $14,3 \%$ & $24,2 \%$ & $50,9 \%$ & $33,6 \%$ \\
\hline & \multirow{2}{*}{ Pública } & Recuento & 18 & 47 & 28 & 93 \\
\hline & & $\%$ percepción cantidad de materiales & $85,7 \%$ & $75,8 \%$ & $49,1 \%$ & $66,4 \%$ \\
\hline \multirow{2}{*}{ Total } & & Recuento & 21 & 62 & 57 & 140 \\
\hline & & $\%$ percepción cantidad de materiales & $100,0 \%$ & $100,0 \%$ & $100,0 \%$ & $100,0 \%$ \\
\hline
\end{tabular}

Tabla 8. Relación entre la calidad de los materiales y el tipo de institución.

\begin{tabular}{|c|c|c|c|c|c|c|c|}
\hline & & & & \multicolumn{3}{|c|}{$\begin{array}{l}\text { PERCEPCIÓN FRENTE A LA CALIDAD } \\
\text { DE MATERIALES EN LA IE }\end{array}$} & \multirow[t]{2}{*}{ Total } \\
\hline & & & & Negativa & Aceptable & Positiva & \\
\hline \multirow{4}{*}{ TIPO DE INSTITUCIÓN } & \multirow{2}{*}{ Privada } & \multicolumn{2}{|l|}{ Recuento } & 1 & 11 & 35 & 47 \\
\hline & & \multicolumn{2}{|c|}{ \% percepción calidad de materiales } & $5,9 \%$ & $20,4 \%$ & $50,7 \%$ & $33,6 \%$ \\
\hline & \multirow{2}{*}{ Pública } & \multicolumn{2}{|l|}{ Recuento } & 16 & 43 & 34 & 93 \\
\hline & & \multicolumn{2}{|c|}{$\%$ percepción calidad de materiales } & $94,1 \%$ & $79,6 \%$ & $49,3 \%$ & $66,4 \%$ \\
\hline \multirow{2}{*}{\multicolumn{2}{|c|}{ Total }} & \multicolumn{2}{|l|}{ Recuento } & 17 & 54 & 69 & 140 \\
\hline & & \multicolumn{2}{|c|}{$\%$ percepción calidad de materiales } & $100,0 \%$ & $100,0 \%$ & $100,0 \%$ & $100,0 \%$ \\
\hline \multirow{3}{*}{\multicolumn{3}{|c|}{$\begin{array}{l}\text { Finalmente, se indagó sobre los temas de capacitación en el } \\
\text { Área de Educación Física. Se destacan la pedagogía y didácti- } \\
\text { ca de la Educación Física, la iniciación y la formación depor- }\end{array}$}} & \multicolumn{2}{|c|}{ Temas de capacitación } & & Frecuencia & Porcentaje \\
\hline & & & \multicolumn{2}{|c|}{ Todo sobre el área } & & 3 & 2,1 \\
\hline & & & \multicolumn{2}{|l|}{ Total } & & 140 & 100,0 \\
\hline
\end{tabular}

tiva, y las capacidades y habilidades físicas.

Tabla 9. Temas de capacitación en el Área de Educación Física, Recreación y Deporte.

\begin{tabular}{lcc}
\hline Temas de capacitación & Frecuencia & Porcentaje \\
\hline Pedagogía y didáctica de la Educación & 36 & 25,7 \\
Física & 29 & 20,7 \\
Iniciación y formación deportiva & 19 & 13,6 \\
Capacidades y habilidades físicas & 11 & 7,9 \\
Otros / ninguno & 9 & 6,4 \\
Competencias & 9 & 6,4 \\
Educación Física y salud & 8 & 5,7 \\
Expresiones lúdico-recreativas & 7 & 5,0 \\
Nuevas tendencias & 6 & 4,3 \\
Expresiones rítmico-danzarias & 3 & 2,1 \\
Educación Física y discapacidad & &
\end{tabular}

La Básica Primaria es atendida, principalmente, por docentes con título de pregrado, con $65,7 \%$, de los cuales solo un 26,4 $\%$ tienen formación específica en Educación Física, recreación y deporte. De estos, la mayoría corresponde a IE privadas, lo cual es estadísticamente significativo $\left(\chi^{2}, \mathrm{p}=0.000\right)$. El 35,7 \% de los docentes poseen especialización, pero la mayoría no están relacionadas con la Educación Física. Por otra parte, 2,9\% de los docentes tienen formación de maestría; sin embargo, solo dos de ellas se relacionan con el área.

Los docentes de Básica Primaria atienden varios grados de este ciclo, al igual que varias áreas; de hecho, la mayoría dicta todas las áreas de su curso (45,7\%). Solo el 26,4\% de los docentes de Básica Primaria tienen dedicación exclusiva a Educación Física, Recreación y Deporte; esto es una realidad más imperante en las IE privadas $\left(\chi^{2}, \mathrm{p}=\right.$ de 0.000$)$.

El Área de Educación Física, Recreación y Deporte es dictada, en promedio, dos horas por semana, distribuidas en dos 
secciones. Ello puede tener implicaciones en los beneficios a la población infantil que la recibe, en términos de lo físico, psicológico y social.

La mayoría de instituciones educativas poseen PIA. La indagación arrojó que hay asociación estadística con el tipo de institución y mostró que es mayor el número de instituciones públicas que no lo poseen $\left(\chi^{2}, \mathrm{p}=0.003\right)$. Además, se detectaron las principales formas de estructurarlo: las mallas curriculares $(40,7 \%)$ y las unidades didácticas $(32,1 \%)$.

Se encontró asociación estadística $\left(\chi^{2}, \mathrm{p}=0.000\right)$ entre la planeación de la clase y el tipo de institución. La mayoría de los docentes que no utilizan un modelo de planeación pertenecen a instituciones públicas. En términos de contenidos, los docentes conocen y describen contenidos propios de la Básica Primaria, pero son utilizados indiscriminadamente en todos los grados de la misma; no hay consenso ni unidad de criterio de contenidos por grado. Además, se encontraron inconsistencias a la hora de describir los elementos didácticos y de planeación del área.

Las principales manifestaciones deportivas, lúdicas y recreativas en las instituciones educativas por parte de los niños de Básica Primaria son las deportivas, en las cuales se destacan el fútbol o microfútbol.

La percepción de los docentes frente al Área de Educación Física, Recreación y Deporte en la Básica Primaria es positiva $(92,9 \%)$. Por el contrario, existen diferencias estadísticamente significativas entre la percepción de la Educación Física ofrecida en la IE y el tipo de institución, asociándose más comúnmente una percepción negativa de la Educación Física a docentes públicos $\left(\chi^{2}, \mathrm{p}=0.000\right)$.

En cuanto a los espacios y materiales para atender el área, tanto en cantidad y calidad, la mayoría de apreciaciones son positivas; sin embargo, existen diferencias estadísticamente significativas $\left(\chi^{2}, \mathrm{p}<0.05\right)$ que muestran que las valoraciones negativas o aceptables frente a estos aspectos son más comunes en instituciones de naturaleza pública.

Los principales temas de capacitación que solicitan los docentes son la pedagogía y didáctica de la Educación Física, la iniciación y la formación deportiva, y las capacidades y habilidades físicas.

Se resalta finalmente que en la ciudad de Medellín existen políticas públicas que benefician el desarrollo de la educación física y el deporte escolar, a partir de lo cual se debe analizar la estructura, la infraestructura, materiales y la dinámica de formación pedagógica permanente que reciben los profesores del campo aplicado de la educación física, para posicionar la presencia de profesores titulados en la básica primaria, adecuar los espacios e instalaciones de las instituciones educativas, mejorar los materiales de los diversos programas que atienden la población infantil y la pertinencia de un programa de formación permanente para los educadores que atienda sus necesidades en temas de actualización pedagógica y di- dáctica especialmente, con lo cual, se pueda estar aportando desde la educación física en el próximo decenio en perspectiva de desarrollo humano, convivencia y Paz en Colombia.

\section{Discusión}

Los datos obtenidos invitan a pensar en la generación de aportes en perspectiva de desarrollo educativo y deportivo en Colombia, desde respuestas a cuestionamientos como ¿Cuáles son las manifestaciones deporte y la educación física escolar en las instituciones de básica primaria del Municipio de Medellín? ¿Cuáles son las manifestaciones extraescolares que promuevan las instituciones educativas del municipio de Medellín referidas al deporte? ¿Cuáles resultados le sirven al deporte y la educación física escolar para adoptar decisiones y cambios en el municipio de Medellín?

Una posible ruta para el desarrollo de la educación física y el deporte escolar es pensarla en términos de dinámicas institucionales que incluyan la formación pedagógica y disciplinar permanente del profesorado, diseñar políticas complementarias que se ocupen y atiendan la formación posgradual o continuada de los profesores escolares en el Municipio de Medellín y continuar las estrategias que los potencien como actores dinámicos, creativos y motivados, para la cualificación del área frente a los avances que hoy el contexto demanda; factores que son validados por Santos Muńoz, S. (2005), Castro Girona, M. J., Piéron, M., \& González Valeiro, M. (2006) y Berenguí Gil, R. \& Garcés de Los Fayos Ruíz, E. J. (2007).

Las reflexiones inmediatas se orientan hacia develar cómo el Estado, el ministerio de Educación, Secretarias de Educación y directivos en las instituciones educativas, se están ocupando de la mejora de la infraestructura física de las instalaciones y materiales para la práctica de la educación física, cómo se ocupan de la formación pedagógica y disciplinar permanente de los profesores que sin tener titulación específica en el área de la educación física, atienden los niños y niñas de la población Medellinense, y en especial, cómo nutrirán la educación básica primaria de docentes cualificados-titulados-especializados. En ésta vía son los aportes de Díaz Suárez, A. (2007) y Moreno Murcia, J. A. \& Cervello Gimeno, E. (2009).

Sin embargo, la motivación del profesorado en el Municipio de Medellín aún es precaria para la formación posgradual, se hace necesario develar si estarán habidos de una formación pedagógica y disciplinar permanente y si contarán con un reconocimiento en tiempos para su desarrollo como profesionales por su asistencia y culminación de estudios de formación complementaria o posgradual; factor que se identifica con las orientaciones de Moreno Murcia, J. A., Alonso Villodre, N., Martínez Galindo, C. \& Cervello Gimeno, E. (2005).

En la perspectiva de las prácticas extraescolares, se hace necesario develar cómo los organismos encaminados a apor- 
tar en la práctica de expresiones deportivas extraescolares como Coldeportes Nacional, Entes Deportivos Departamentales y Entes Deportivos Municipales, se ocupan de un diseńo concatenado, estructurado, congruente y coherente con las metas de desarrollo deportivo que se tenga en la mirada de País, metas que implican lo deportivo, lo social, lo ambiental y lo físico, como el planteamiento de Cecchini Estrada, J. A., González González-Mesa, C., Méndez Giménez, A., Fernández-Río, J., Contreras Jordán, O. \& Romero Granados, S. (2008).

Se abren entonces, espacios para pensar desde las escuelas, sus articulaciones hacia procesos de formación hacia altos logros, donde el Comité Olímpico Colombiano reciba de sus ligas y federaciones, procesos formativos con calidad, que se originan en las escuelas y sus procesos deportivos extraescolares, sin embargo el sistema aún no se evidencia como factor articulado, congruente a un sueńo de País en lo formativo y deportivo desde el contexto escolar. Factor que a la vez, genera nuevas relaciones para potenciar los escolares desde habilidades para la vida, la experiencia de nuevas modalidades y expresiones deportivas, la participación y equidad ante posibilidades de desarrollo deportivo, en toda aquella población infantil y juvenil que no ostenta una participación competitiva o encaminada a altos logros; factor a desarrollar con ahínco desde las reflexiones de Padierna Cardona (2010), Grupo de Cultura Somática (2010), Padierna Cardona, J. C., \& Palacio González, E. V. (2013) y Padierna Cardona, J. C., Palacio González, E. V. \& Cardona Mejía, L.M. (2015).

Es posible entonces, pensar una reestructuración de la asignación horaria y de las dinámicas extraescolares que hoy vive la Educación Física como área de desarrollo educativo y deportivo en el Municipio de Medellín, donde dada su autonomía pueda pensar en nuevas formas de atender el desarrollo de su infraestructura, sus profesores, su financiación y se puedan beneficiar los niños y niñas que día a día, participan y de éstos dos aspectos de la Educación Física. En sí, hay acciones desde cada estrategia (educativa y formativa) que deberán ir encontrando las articulaciones pertinentes para continuar brindándole calidad, visibilidad e impacto, al sueño de País que se gesta en los planes de desarrollo educativo y deportivo desde el Municipio de Medellín.

Las dificultades del estudio se presentaron a la hora de la comunicación y autorización institucional para que docentes y directivos fuesen partícipes y conocedores de las intencionalidades del estudio, donde la búsqueda de acciones fomentadoras de la Educación Física y el Deporte Escolar por parte del Instituto Municipal de Deportes y Recreación-INDER Medellín, pretendió concientizar y analizar una realidad que hoy debe ser cualificada desde estrategias para la mejora de instalaciones físicas y la creación de planes de formación, gestionando la cualificación del profesorado y su articulación a políticas públicas que impacten el área.
Las futuras líneas de investigación que se generan del estudio están centradas desde lo educativo en la identificación de teorías, prácticas y discursos que habitan la formación inicial y posgradual de los profesionales que atienden la educación física en el Municipio de Medellín, develando su motivación, implicación y liderazgo para la cualificación pedagógica y disciplinar permanente y posgradual, como una posible estrategia nuclear para el desarrollo del área.

En la identificación de acciones que posibiliten un seguimiento y cualificación de la infraestructura física con que cuenta el municipio de Medellín, para brindar mejoras y programas que articulen lo social, lo ambiental y el entorno. Quizás pensar en procesos de gestión de los escenarios deportivos en las instituciones educativas en asocio con el instituto municipal del deporte, pueda optimizar la asignación de espacios y recursos en pro de un plan estratégico para el desarrollo del área y el deporte formativo hacia las metas deportivas del departamento y el País.

A la vez, las instituciones educativas están constantemente sometidas a situaciones de cambio, donde atienden las demandas del entorno en el contexto global y competitivo, con lo cual se evidencia la necesidad de indagar por la sostenibilidad, desarrollo y posibilidades de cambio en las mismas para adaptarse, ser flexibles y articularse con las características de mundo contemporáneo que habitamos.

Éstas acciones impactaran en gran medida, un cambio en instituciones (escolares y universitarias), organizaciones deportivas (Entes Municipales del deporte, clubes, ligas, federaciones) y actores (profesores, directivos, entrenadores, políti$\cos )$ que día a día se ven inmersos en problemas, expectativas, preocupaciones, dinámicas, estrategias y ámbitos de la formación pedagógica y disciplinar de profesores y directivos en el Municipio de Medellín.

Quizás llevar a otros contextos estas reflexiones, permita continuar en la vía de la innovación, el desarrollo y el impacto esperado de los procesos formativos y deportivos del $\mathrm{Mu}$ nicipio de Medellín hacia la calidad y visibilidad del Departamento en el País, factor que posiblemente deba ser analizado y desarrollado también, desde el profesorado universitario en el campo de conocimiento de la Educación Física.

Desde lo deportivo en el ámbito extraescolar, las futuras investigaciones deben generar sinergias entre las demandas de las comunidades, la capacidad física del entorno y las planificaciones del desarrollo deportivo (en infraestructura y programas) desde las escuelas y los entes deportivos municipal y departamental, como acción articulada a sueños de País y sus estamentos de Coldeportes Nacional y el Comité Olímpico Colombiano. Es imperioso también, que las instancias públicas asuman un compromiso de crecimiento ante nuevas prácticas deportivas u optimización de la infraestructura física existente, para atender las demandas deportivas de las comunidades actuales del Municipio de Medellín. 
Se puede concluir de forma siempre inicial, que el presente estudio se articula con la administración deportiva, el diseño de políticas públicas en educación y deporte, la implementación de procesos de cambio en las instituciones educativas (escolares y universitarias), la formación inicial, la formación pedagógica y disciplinar permanente de profesionales, la formación posgradual y continua de profesores universitarios para atender de forma estratégica, articulada y congruente, el crecimiento del campo de conocimiento de la Educación Física en Colombia.

\section{Referencias}

1. Alcaldía de Medellín. (2012). Plan de Desarrollo Municipal: Medellín un Hogar para la Vida. Recuperado: http://www.medellin.gov.co/ $\mathrm{irj} / \mathrm{go} / \mathrm{km} /$ docs/wpccontent/Sites/Subportal\%20del\%20Ciudadano/ Plan\%20de\%20Desarrollo/Secciones/Publicaciones/Documentos/PlaDesarrollo2012-2015/2012-04-30_Proyecto\%20de\%20acuerdo\%20 VERSION\%20COMPLETA.pdf

2. Blázquez, D. (1995). La iniciación deportiva y el deporte escolar. Barcelona: INDE.

3. Berenguí Gil, R. \& Garcés de Los Fayos Ruíz, E. J. (2007). Valores en el deporte escolar: estudio con profesores de educación física. Cuadernos de psicología del deporte. En: Digitum Biblioteca Universitaria de la Universidad de Murcia. 7(2), 89-103.

4. Bonilla Baquero, C. B. (1996). Didáctica de la Educación Física de base. Armenia: kinesis.

5. Briones, G. (1986). Métodos y técnicas de investigación para las ciencias sociales. México: Editorial trillas.

6. Bustamante, S. A., Chaverra, B., y González Palacio, E. V. (2011). La cultura corporal de niños y niñas de una institución educativa. Saarbrücken, Alemania: Editorial Académica Española.

7. Camacho Coy, H. (2003). Pedagogía y didáctica de la Educación Física. Armenia: Kinesis.

8. Castańer i Balcells, M., y Olecguer i Foguet, O. (1991). Una propuesta de sistematización de elementos constituyentes de la motricidad infantil. Apunts: Educació Física i Esports (26), 15-22.

9. Castro Girona, M. J., Piéron, M., \& González Valeiro, M. (2006). Actitudes y motivación en educación física escolar. En: Retos: nuevas tendencias en educación física, deporte y recreación. (10), 5-22.

10. Cecchini Estrada, J. A., González González-Mesa, C., Méndez Giménez, A., Fernández-Río, J., Contreras Jordán, O. \& Romero Granados, S. (2008). Metas sociales y de logro, persistencia-esfuerzo e intenciones de práctica deportiva en el alumnado de Educación Física. Psicothema, 20(2), 260-265.

11. COLDEPORTES Nacional. (2001). Legislación deportiva. Armenia: Kinesis.

12. Congreso de la República de Colombia. (1994). Ley 115 de 1994 / Ley General de Educación.

13. Congreso de la República de Colombia. (1995). Ley 181 de 1995 / Ley del deporte.

14. Contreras, J. (1998). Didáctica de la Educación Física. Barcelona: INDE.

15. Devís, J. (1995). Deporte, educación y sociedad: hacia, un deporte escolar diferente. Revista de Educación, (306), 455-472.

16. Díaz Suárez, A. (2007). La Educación Física y el deporte escolar en la Región de Murcia. Retos: nuevas tendencias en educación física, deporte y recreación, (11), 26-32.

17. Díaz Suárez, A., y Martínez Moreno, A. (diciembre de 2003). Deporte escolar y educativo. Efdeportes, 9(67), 1. Recuperado de http://www.efdeportes.com/efd67/educat.htm.

18. Elias, N., y Dunning, E. (1992). Deporte y ocio en el proceso de civilización. España: Fondo de Cultura Económica.

19. Gil-Madrona, P., Contreras Jordán, O. R., Gómez Víllora, S., y Gómez Barreto, I. (julio-diciembre 2008). Justificación de la Educación Física en la educación infantil. Educación y educadores, 11(2), 159-174.

20. Grau, M., \& Soler, S. (2003). Actitudes, valores y normas en la educa- ción física y el deporte. Editorial Inde. España.

21. Gobernación de Antioquia. (2009). Guía curricular para la Educación Física. Medellín: Litoimpresos y Servicios Ltda.

22. Gobernación de Antioquia. (2011). Estándares básicos de competencias para el Área de Educación Física, Recreación y Deporte formativo en el departamento de Antioquia. Medellín: Litoimpresos y Servicios S. A. S.

23. Gobernación de Antioquia. (2012). Plan de Desarrollo Departamental: Antioquia la más Educada. Recuperado de: http://www.antioquia.gov. co/Plan_de_desarrollo_2012_2015/PDD_FINAL/PDD_FINAL/3_ Fundamentos.pdf

24. Grisales, H. (2000). Muestreo en estudios descriptivos. Medellín: Universidad de Antioquia.

25. INDEPORTES Antioquia. (2010). Plan decenal del deporte, la recreación, la educación física y la actividad física, para el desarrollo humano, la convivencia y la paz 2009-2019. Bogotá: Virtual Box Imagen \& Comunicación.

26. Instituto de Deportes y Recreación de Medellín. (2007). Plan estratégico del deporte y la recreación 2007-2017. Medellín: INDER.

27. López Parralo, M. J. (mayo de 2006). Características básicas del deporte en la escuela. Efdeportes, 11 (96), 1. Recuperado de http://www.efdeportes.com/efd96/escuela.htm.

28. Ministerio de Educación Nacional. (1997). Decreto Reglamentario 1860 de 1994. Bogotá: El Pensador.

29. Ministerio de Educación Nacional. (2003). Lineamientos curriculares para el Área de la Educación Física, la Recreación y el Deporte. Bogotá: Magisterio.

30. Ministerio de Educación Nacional. (2004). Ley 934 de 2004. Bogotá.

31. Ministerio de Educación Nacional. (2010). Orientaciones pedagógicas para la Educación Física, Recreación y Deporte. Bogotá: Ministerio de Educación Nacional.

32. Moreno Murcia, J. A., Alonso Villodre, N., Martínez Galindo, C. \& Cervello Gimeno, E. (2005). Motivación, disciplina, coeducación y estado de flow en educación física: Diferencias según la satisfacción, la práctica deportiva y la frecuencia de práctica. Cuadernos de psicología del deporte, 5(1), 231-243.

33. Moreno Murcia, J. A. \& Cervello Gimeno, E. (2009). Pensamiento del alumno hacia la Educación Física: su relación con la práctica deportiva y el carácter del educador. Enseńanza \& Teaching, 21.

34. Padierna Cardona, J.C. (2010). El perfil pedagógico competente: un análisis a la luz del formador de formadores en la Licenciatura en Educación Física y Deportes de la Universidad de San Buenaventura, Medellin, 2010. En Revista educación física y deporte. 29 (2), p. 269-276.

35. Padierna Cardona, J. C., \& González Palacio, E. V. (2013). La metodología experiencial en la Educación Superior. Itinerario Educativo, 27(62), 151-168.

36. Padierna Cardona, J. C., González Palacio, E. V. \& Cardona Mejía, L.M. (2015). Metodología Experiencial: Una ruta para la enseñanza aprendizaje de la educación física en la educación superior. Colombia: Ed. Bonaventuriana.

37. Polit, D., y Hungler, B. (2000). Investigación cientifica en ciencias de la salud. México: Mc Graw-Hill.

38. Rodríguez Castellón, J. J. (marzo de 2010). La iniciación deportiva en el contexto escolar: análisis de los modelos de enseńanza. Efdeportes, (142), 
1. Recuperado de http://www.efdeportes.com/efd142/la-iniciacion-deportiva-en-el-contexto-escolar.htm.

39. Sanmartín, M. G. (2004). El valor del deporte en la educación integral del ser humano. Revista de educación, (335), 105-126.
40. Santos Muñoz, S. (2005). La Educación Física escolar ante el problema de la obesidad y el sobrepeso. Revista Internacional de medicina y Ciencias de la Actividad Física y el Deporte, 5(19), 179-199. 